\title{
QRS voltage of the electrocardiogram and Frank vectorcardiogram in relation to ventricular volume
}

\author{
S. TALBOT, D. KILPATRICK, A. JONATHAN, AND M. J. RAPHAEL \\ From the Division of Cardiovascular Disease and Department of Radiology, Hammersmith Hospital, \\ Ducane Road, London
}

\begin{abstract}
Left ventricular volumes were estimated in 59 patients, who were investigated by single plane ventriculography and coronary arteriography. The relation of the left ventricular end-diastolic volumes to the $Q R S$ voltage of the 12-lead electrocardiograms and Frank vectorcardiograms was examined. It was found that the maximum spatial $Q R S$ voltage and the $R$ wave voltage of leads V5 and V6 in patients without left ventricular hypertrophy were inversely correlated with end-diastolic volume.

This inverse relation of $Q R S$ voltage and left ventricular volume may explain loss of $Q R S$ voltage with dilatation of the heart. In patients with left ventricular hypertrophy $Q R S$ voltage is usually positively correlated with the degree of hypertrophy, but there is no significant correlation in the presence of cardiac dilatation. If the results of this study are extrapolated to patients with left ventricular hypertrophy an cardiac dilatation, then the inverse correlation of volume and $Q R S$ voltage may reduce the diagnostic sensitivity of unipolar chest lead and vectorcardiographic criteria of left ventricular hypertrophy.
\end{abstract}

Left ventricular wall thickness and mass have been correlated with QRS voltage of the 12-lead electrocardiogram and Frank vectorcardiogram; in life these measurements were made from the left ventriculogram (Hugenholtz et al., 1968; Vine et al., 1971) or by echocardiography (Bennett and Evans, 1974). QRS voltage has also been positively correlated with left ventricular end-diastolic volume (Baxley et al., 1968; Vine et al., 1971), but these studies have not distinguished the correlation with volume overloading of the left ventricle associated with left ventricular hypertrophy from any correlation of $Q R S$ voltage with volume alone.

The volume of the left ventricle is increased in many patients with left ventricular hypertrophy but the relation of QRS voltage to volume, in the absence of left ventricular hypertrophy, is unknown. This study explored these relations in patients without left ventricular hypertrophy and independently of variation of left ventricular mass.

\section{Methods}

Fifty-nine patients undergoing routine investigation for suspected coronary artery disease were included in the study. Thirty-six other patients examined were excluded from the study because of left ventricular aneurysm, other cardiovascular disease or intraventricular conduction defects. In all patients left ventriculograms and coronary arteriograms showed the wall and chamber of the left ventricle clearly when the heart rhythm was regular.

Routine 15-lead electrocardiograms, permitting derivation of the frontal and horizontal plane Frank vectorcardiograms, were performed on all patients. From these recordings the voltages of the $R$ wave in leads $\mathrm{X}, \mathrm{Y}, \mathrm{Z}, \mathrm{aVL}, \mathrm{V} 5$, and V6 were measured. In addition the magnitude of the maximal spatial QRS voltage was computed from the simultaneous orthogonal vectors using the equation:

Spatial $\mathrm{QRS}$ voltage $=\sqrt{\mathrm{RX}^{2}+\mathrm{RY}^{2}+\mathrm{RZ}^{2}}$ (Whitham, 1975) where RX, RY, RZ are the voltages of the $Q R S$ vector projected on the $\mathrm{X}, \mathrm{Y}$, and $Z$ axes, respectively.

The QRS duration and the electrical axis of each 12-lead scalar electrocardiogram were also determined.

Left ventricular volumes were calculated by the area-length method (Kasser and Kennedy, 1969), using electronic planimetry by the same method as that of Sharma et al. (1976). Mean left ventricular wall thickness was derived from a planimetered area $4 \mathrm{~cm}$ in length along the anterior cardiac border at 
end-diastole; from the left ventricular wall thickness, and the total left ventricular volume at enddiastole, the left ventricular wall volume was calculated (Rackley et al., 1964). The left ventricular mass was derived using 1.05 as the density of cardiac muscle (Bardeen, 1918).

The left ventricular volumes and $Q R S$ voltages were measured independently.

\section{Results}

Studies were made on 41 men and 18 women. The number of patients with normal left ventriculograms, the number with dyskinesia, and the number with left ventricular hypertrophy (left ventricular mass $\geqslant 230 \mathrm{~g}$-Kennedy et al., 1966) are presented in Table 1. To describe the relation between QRS voltage and volume clearly, these patients have been divided into three groups: (1) Patients with normal coronary arteries who did not have left ventricular hypertrophy (21); (2) Patients with

Table 1 The left ventricular wall

\begin{tabular}{|c|c|c|c|c|c|}
\hline & $\begin{array}{l}\text { Normal } \\
\text { arteries } \\
\text { Men }\end{array}$ & $\begin{array}{l}\text { coronary } \\
\text { Women }\end{array}$ & $\begin{array}{l}\text { Coronar } \\
\text { disease } \\
\text { Men }\end{array}$ & $\begin{array}{l}\text { ry artery } \\
\text { Women }\end{array}$ & Total \\
\hline $\begin{array}{l}\text { Normal thickness and } \\
\text { function }\end{array}$ & 10 & 9 & 7 & 17 & 27 \\
\hline $\begin{array}{l}\text { Normal thickness with } \\
\text { dyskinesia }\end{array}$ & 1 & $1\}^{21}$ & 14 & $5\} 27$ & 21 \\
\hline $\begin{array}{l}\text { Left ventricular } \\
\text { hypertrophy }\end{array}$ & 2 & 2 & 7 & 0 & 11 \\
\hline Total & 13 & 12 & 28 & 6 & 59 \\
\hline
\end{tabular}

coronary artery disease who did not have left ventricular hypertrophy (27); (3) Patients with left ventricular hypertrophy whatever the anatomy of the coronary arteries and the function of the left ventricle (11).

The left ventricular volumes, left ventricular masses, wall thicknesses, and QRS voltages for the first group are shown in Table 2; similar measurements for the second group are presented in Table 3. The maximum spatial QRS voltage was inversely correlated with volume for group 1 (Fig. 1) and for group 2 (Fig. 2); both correlations were the same $(r=0.68)$ and were significant at the 1 per cent level. There was no significant correlation for the group of patients with left ventricular hypertrophy.

The $R$ wave voltages in leads V5 and V6 were also inversely correlated with left ventricular volume in groups 1 and 2 , but these correlations were not significant in these small samples (group 1: $=-0.46, P=0.03$; group 2: $r=-0.21, P=0.17$ ). The voltage of the $R$ wave in lead aVL, however, was positively, though also not significantly, correlated with volume in group 1 and group $2(r=0.35$, $P=0 \cdot 12$, and $r=0 \cdot 24, P=0 \cdot 10$, respectively).

The maximum spatial $Q R S$ voltage was not significantly correlated with either left ventricular wall thickness or mass in patients without left ventricular hypertrophy but the numbers are small. There were also no significant correlations of left ventricular wall thickness, mass, or end-diastolic volume with any voltage measurement in patients with left ventricular hypertrophy (group 3).

Table $2 Q R S$ voltage, left ventricular volume and mass in patients with normal coronary arteries (group 1)

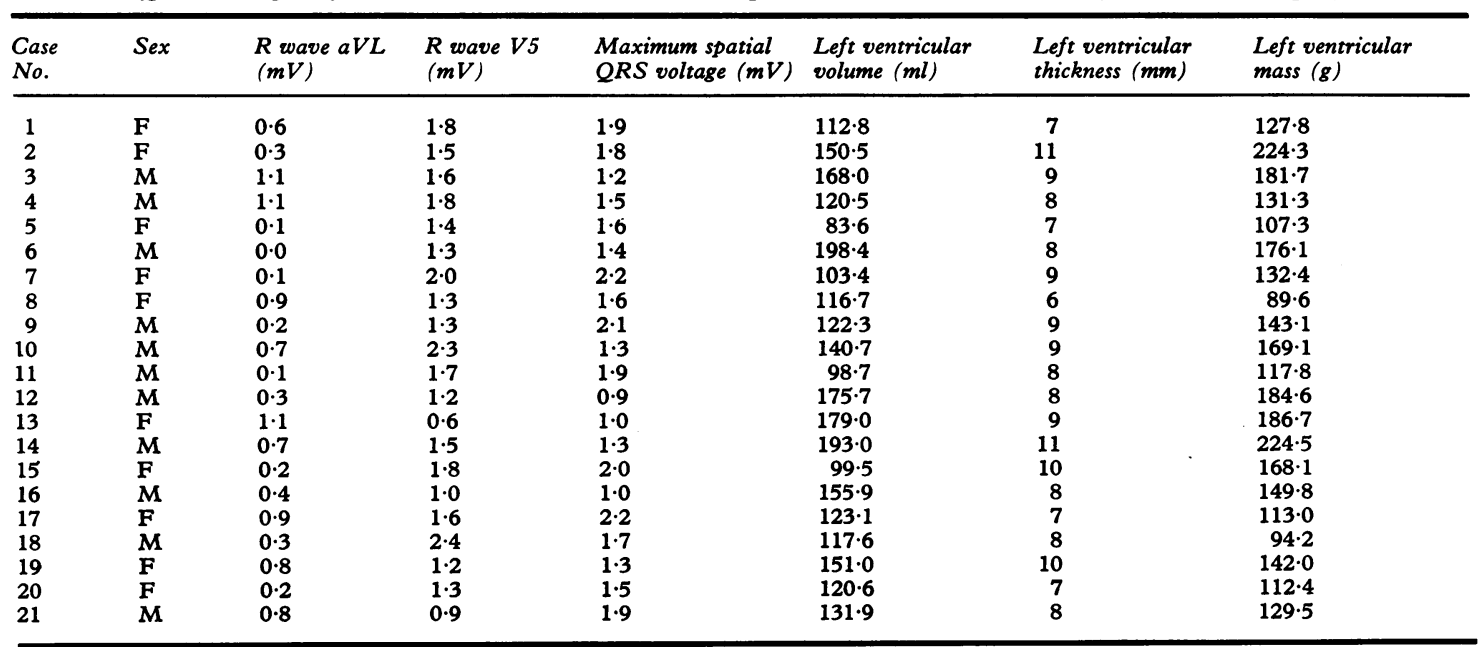


A multiple regression equation was calculated from the data of groups 1 and 2 for the two independent variables, left ventricular wall thickness and left ventricular volume, and for the dependent variable, maximum spatial $Q R S$ voltage:

Maximum spatial $Q R S$ voltage $(\mathrm{mV})=1.34+$ 0.016 th -0.002 vol, where th is the left ventricular

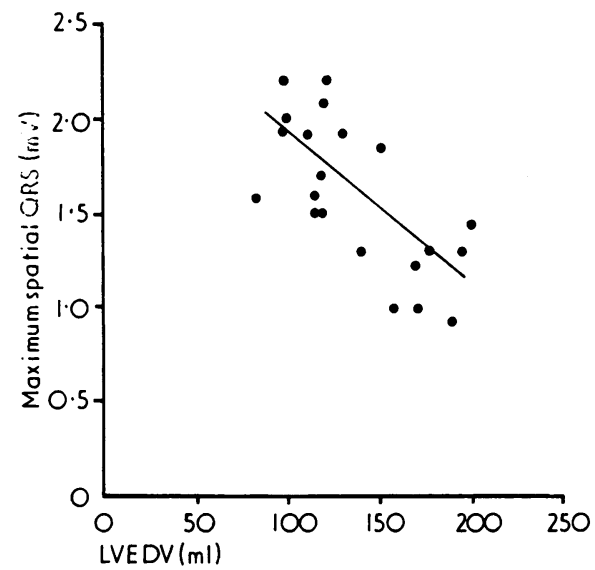

Fig. 1 The maximum spatial $Q R S$ voltage in $m V$ is plotted on the ordinate and the left ventricular enddiastolic volume ( $\mathrm{ml}$ ) is plotted on the abscissa for the patients with normal coronary arteries (group 1). The regression line is shown. wall thickness in mm and vol is the left ventricular volume in $\mathrm{ml}$.

\section{Discussion}

This study has shown that in a selected group of patients without left ventricular hypertrophy, who

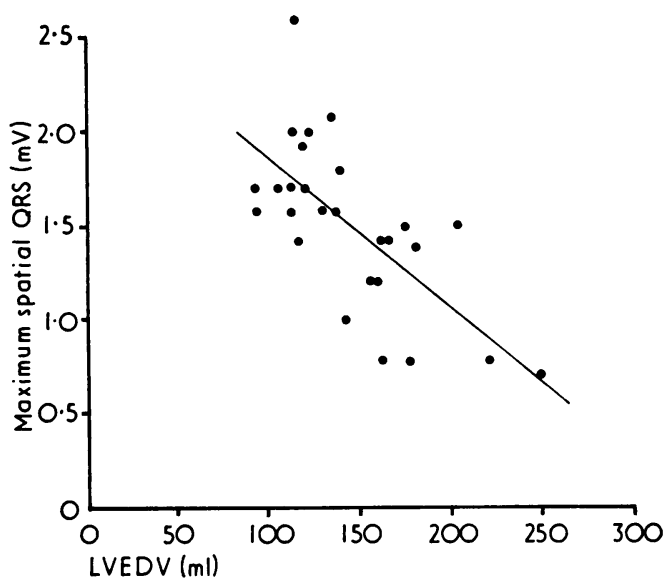

Fig. 2 The maximum spatial $Q R S$ voltage in $m V$ is plotted on the ordinate and the left ventricular enddiastolic volume ( $\mathrm{ml}$ ) is plotted on the abscissa for the patients with coronary artery disease (group 2). The regression line is shown.

Table $3 Q R S$ voltage, left ventricular volume, and mass in patients with coronary artery disease (group 2)

\begin{tabular}{|c|c|c|c|c|c|c|c|}
\hline $\begin{array}{l}\text { Case } \\
\text { No. }\end{array}$ & $\operatorname{Sex}$ & $\begin{array}{l}R \text { wave } a V L \\
(m V)\end{array}$ & $\begin{array}{l}R \text { wave } V 5 \\
(m V)\end{array}$ & $\begin{array}{l}\text { Maximum spatial } \\
\text { QRS voltage }(m V)\end{array}$ & $\begin{array}{l}\text { Left ventricular } \\
\text { volume (ml) }\end{array}$ & $\begin{array}{l}\text { Left ventricular } \\
\text { thickness (mm) }\end{array}$ & $\begin{array}{l}\text { Left ventricular } \\
\text { mass }(g)\end{array}$ \\
\hline $\begin{array}{l}22 \\
23 \\
24 \\
25 \\
26 \\
27 \\
28 \\
29 \\
30 \\
31 \\
32 \\
33 \\
34 \\
35 \\
36 \\
37 \\
38 \\
39 \\
40 \\
41 \\
42 \\
43 \\
44 \\
45 \\
46 \\
47 \\
48\end{array}$ & $\begin{array}{l}M \\
M \\
F \\
F \\
M \\
F \\
M \\
M \\
F \\
M \\
M \\
M \\
M \\
F \\
M \\
M \\
F \\
M \\
M \\
M \\
M \\
M \\
M \\
M \\
M \\
M \\
M\end{array}$ & $\begin{array}{l}0.6 \\
0.2 \\
0.2 \\
0.4 \\
1.1 \\
0.4 \\
0.1 \\
1.5 \\
0.3 \\
0.0 \\
0.2 \\
0.8 \\
0.5 \\
0.6 \\
1.0 \\
0.2 \\
0.6 \\
0.4 \\
0.5 \\
0.8 \\
0.2 \\
0.3 \\
0.7 \\
0.3 \\
0.3 \\
0.6 \\
0.7\end{array}$ & $\begin{array}{l}1 \cdot 4 \\
0.8 \\
2.5 \\
2.3 \\
1.2 \\
2 \cdot 1 \\
1.2 \\
1.0 \\
1.1 \\
1.4 \\
1.3 \\
0.9 \\
1.2 \\
1.3 \\
1.2 \\
1.3 \\
0.2 \\
0.9 \\
1.3 \\
1 \cdot 1 \\
0.5 \\
2.2 \\
1.4 \\
1.1 \\
0.7 \\
1.6 \\
1.0\end{array}$ & $\begin{array}{l}2.0 \\
0.7 \\
2.6 \\
1.8 \\
1.9 \\
1.6 \\
1.7 \\
1.5 \\
1.6 \\
1.6 \\
1.2 \\
1.7 \\
1.4 \\
1.6 \\
1.4 \\
1.0 \\
0.8 \\
0.8 \\
1.2 \\
1.7 \\
1.4 \\
2.0 \\
2.1 \\
1.5 \\
0.8 \\
1.7 \\
1.4\end{array}$ & $\begin{array}{r}122 \cdot 0 \\
243 \cdot 9 \\
115 \cdot 1 \\
139 \cdot 0 \\
118 \cdot 7 \\
112 \cdot 8 \\
120 \cdot 0 \\
203 \cdot 9 \\
129 \cdot 1 \\
136 \cdot 0 \\
156 \cdot 0 \\
107 \cdot 3 \\
162 \cdot 0 \\
93 \cdot 6 \\
164 \cdot 3 \\
142 \cdot 0 \\
178 \cdot 1 \\
162 \cdot 0 \\
159 \cdot 0 \\
112 \cdot 0 \\
120 \cdot 8 \\
114 \cdot 6 \\
135 \cdot 3 \\
176 \cdot 9 \\
220 \cdot 9 \\
94 \cdot 1 \\
182 \cdot 8\end{array}$ & $\begin{array}{r}10 \\
7 \\
10 \\
9 \\
11 \\
8 \\
11 \\
8 \\
8 \\
11 \\
11 \\
6 \\
11 \\
8 \\
9 \\
9 \\
9 \\
11 \\
8 \\
8 \\
8 \\
9 \\
9 \\
10 \\
6 \\
6 \\
10\end{array}$ & $\begin{array}{r}174 \cdot 5 \\
225 \cdot 4 \\
170 \cdot 2 \\
162 \cdot 8 \\
219 \cdot 5 \\
127 \cdot 8 \\
105 \cdot 0 \\
177 \cdot 9 \\
137 \cdot 9 \\
203 \cdot 6 \\
224 \cdot 7 \\
85 \cdot 9 \\
226 \cdot 1 \\
114 \cdot 3 \\
184 \cdot 6 \\
165 \cdot 5 \\
191 \cdot 0 \\
229 \cdot 2 \\
153 \cdot 1 \\
123 \cdot 9 \\
129 \cdot 8 \\
146 \cdot 7 \\
171 \cdot 5 \\
216 \cdot 0 \\
238 \cdot 4 \\
96 \cdot 5 \\
222 \cdot 3\end{array}$ \\
\hline
\end{tabular}


underwent coronary arteriography and left ventriculography for suspected coronary artery disease, the end-diastolic volume is inversely related to the maximum spatial QRS voltage of the Frank corrected vectorcardiogram. This was found whether the patients had coronary artery disease or not and was also found in the presence of dyskinesia despite the obvious departure of left ventricular shape from the ellipsoid formula. It was not found in a small group of patients with left ventricular hypertrophy, probably because of the opposite effect of hypertrophy on $Q R S$ voltage.

Day-to-day variation of the voltage of the electrocardiogram, vectorcardiogram, and the left ventricular volume are well known (Willems et al., 1972). The calculation of left ventricular volume from single plane left ventriculograms has its limitations, being based on a hypothetical ellipsoid shape of the ventricle (Greene et al., 1967), but measurements from biplane ventriculograms are only slightly more accurate (Dodge et al., 1962; Baxley et al., 1968; Kennedy et al., 1970). However, errors introduced by these factors should tend to obscure any relation of $Q R S$ voltage to left ventricular volume and not accentuate it.

The electrocardiographic diagnosis of left ventricular hypertrophy is based on QRS voltage measurements and repolarisation changes of both the 12lead electrocardiogram (Sokolow and Lyon, 1949) and the Frank vectorcardiogram. It is generally accepted that all voltage criteria are of similar diagnostic value, but there is little evidence for this. It has been found that an $R$ wave voltage in lead aVL or over $1.0 \mathrm{mV}$ indicates left ventricular hypertrophy (Talbot et al., 1976). However, this criterion is only specific in the presence of a normal electrical axis, and is not as sensitive as either the maximal spatial QRS voltage, or criteria based on $R$ wave voltage in leads V5 and V6. With the development of cardiac dilatation there is a diminution of the voltage of the $R$ wave in leads V5 and V6, and therefore voltage criteria based on these leads become less sensitive. In a recent study these results were confirmed and in addition it was found that the voltage of the $R$ wave in lead aVL was preserved in patients with left ventricular hypertrophy and cardiac dilatation (Talbot, 1975).

Rotation of the electrical axis superiorly and posteriorly which occurs in association with cardiac dilatation may partly explain these results. However, the position of the heart and the electrical axis do not affect the maximum spatial $Q R S$ voltage and yet this measurement is only slightly more sensitive to left ventricular hypertrophy than the praecordial voltage criteria of Sokolow and Lyon (Talbot et al., 1976). This present study suggests that cardiac dilatation also affects the maximum spatial QRS voltage and it confirms that the voltage of the $R$ wave in lead aVL is not inversely correlated with left ventricular volume. Since the QRS voltage in leads V5 and V6 is closely related to the maximum spatial $Q R S$ voltage, reduction of $R$ wave voltage in these leads is to be expected, though other mechanisms may also play a part.

The discrepancy between the voltage of the $R$ wave in lead aVL and the other voltage measurements in this study has not been explained, but discrepancies in voltage criteria of left ventricular hypertrophy between patients are well known. This is a good justification for multiple electrocardiographic leads.

Hugenholtz et al. (1968) have suggested without proof that QRS voltage is inversely correlated to volume but the reason for this association is unknown.

Bayley and Berry (1963) have suggested that increased intracavitary conductivity resulting from increased blood volume will augment the QRS voltage by local effects on the dipoles in the cardiac muscle (the Brody effect as first described by Brody (1956)). In addition, the proximity of the enlarged heart to the anterior chest wall will tend to increase the potential field in those areas, and Bayley and Berry (1963) have suggested that the surface potential may increase directly with the radius of the ventricular sphere. If so, these effects do not increase the voltage of the $R$ wave in leads V5 and V6 in man, because of other influences.

However, if one considers the effect of the volume of blood on the dipolar activation fronts existing in the left ventricle it is not surprising that a reduction in the external electrical field is related to an increase in volume. As the volume increases, the internal surface of the left ventricle increases thus allowing more units, whether single dipoles or activation fronts, to have the highly conductive blood as the adjacent medium on at least one side. This will increase internal current flow which will have the effect of short circuiting some of the electrical field and hence reducing the external field.

In complex situations other effects may be important, but experimentally the reduction in QRS voltage with dilatation suggests that either the increased blood volume reduces the voltage by a short-circuiting effect or that in the dilated heart fewer muscle units are electrically active. All these theories are tentative since the relation of QRS voltage to left ventricular mass does not prove that muscle mass is the primary determinant of QRS voltage or that the distribution of left ventricular muscle and wall thickness are unimportant. Many 
studies that have correlated QRS voltage with left ventricular volume and mass have been very selective, usually excluding patients with ischaemia (Vine et al., 1971) and not differentiating eccentric from concentric hypertrophy. In all studies correlations have only been moderate and the relation of mass to QRS voltage has deteriorated when the lesions were complex. Though these effects have not been quantified, it is felt that mixed types of overload, conduction disturbances, combined ventricular enlargement, congestive heart failure, and associated pulmonary and ischaemic heart disease, affect the relation of $Q R S$ voltage to left ventricular hypertrophy (Whitham, 1975).

If the association of left ventricular volume and QRS voltage could be extrapolated to changes in individual patients it might explain loss of voltage with the onset of cardiac dilatation in the presence of pressure overload of the left ventricle and absence of voltage criteria of left ventricular hypertrophy in the presence of left ventricular hypertrophy resulting from volume overload. However, more sophisticated statistical analysis of larger numbers of patients with left ventricular hypertrophy and varying degrees of volume overload will be needed to confirm this view.

\section{References}

Bardeen, C. R. (1918). Determination of the size of the heart by means of the $x$-rays. American fournal of Anatomy, 23, 423-487.

Baxley, W. A., Dodge, H. T., and Sandler, H. (1968). A quantitative angiocardiographic study of left ventricular hypertrophy and the electrocardiogram. Circulation, 37, 509-517.

Bayley, R. H., and Berry, P. M. (1963). 'Body surface' potentials produced by the eccentric dipole in the heart wall of the non-homogenous volume conductor. American Heart fournal, 65, 200-207.

Bennett, D. H., and Evans, D. W. (1974). Correlation of left ventricular mass determined by echocardiography with vectorcardiographic and electrocardiographic voltage measurements. British Heart fournal, 36, 981-987.

Brody, D. A. (1956). Theoretical analysis of intracavitary blood mass influence on the heart-lead relationship. Circulation Research, 4, 731-738.

Dodge, H. T., Hay, R. E., and Sandler, H. (1962). Angiocardiographic method for directly determining left ventricular stroke-volume in man. Circulation Research, 11, 739-745.
Greene, D. G., Carlisle, R., Grant, C., and Bunnell, I. L. (1967). Estimation of left ventricular volume by one plane cineangiography. Circulation, 35, 61-69.

Hugenholtz, P. G., Ellison, R. C., and Mietinen, O. S. (1968). Spatial voltages in the assessment of left ventricular hypertrophy (Frank system). Fournal of Electrocardiology, 1, 77-90.

Kasser, I. S., and Kennedy, J. W. (1969). Measurement of left ventricular volumes in man by single-plane cineangiocardiography. Investigative Radiology, 4, 83-90.

Kennedy, J. W., Baxley, W. A., Figley, M. M., Dodge, H. T., and Blackmon, J. R. (1966). Quantitative angiocardiography. I. Normal left ventricle in man. Circulation, 34, 272-278.

Kennedy, J. W., Trenholme, S. E., and Kasser, I. S. (1970). Left ventricular volume and mass from single plane cineangiocardiogram. A comparison of anteroposterior and right anterior oblique methods. American Heart fournal, 80, 343-352.

Rackley, C. E., Dodge, H. T., Coble, Y. D., and Hay, R. E. (1964). Method for determining left ventricular mass in man. Circulation, 29, 666-671.

Sharma, B., Goodwin, J. F., Raphael, M. J. Steiner, R. E., Rainbow, R. G., and Taylor, S. H. (1976). Left ventricular angiography on exercise. A new method of assessing left ventricular function in ischaemic heart disease. British Heart Fournal, 38, 59-70.

Sokolow, M., and Lyon, T. P. (1949). The ventricular complex in left ventricular hypertrophy as obtained by unipolar precordial and limb leads. American Heart fournal, 37, 161-186.

Talbot, S. (1975). Electrical axis and voltage criteria of left ventricular hypertrophy. American Heart fournal, 90, 420-425.

Talbot, S., Dreifus, L. S., Watanabe, Y., Chiang, R., Morris, K., and Reich, M. (1976). Diagnostic criteria for computeraided electrocardiographic 15 lead system. British Heart Fournal, 38, 1247-1261.

Vine, D. L., Finchum, R. N., Dodge, H. T., Bancroft, W. H., Jr., and Hurst, D. C. (1971). Comparison of the vectorcardiogram with the electrocardiogram in the prediction of left ventricular size. Circulation, 43, 547-558.

Whitham, A. C. (1975). A System of Vectorcardiographic Interpretation. Year Book Medical Publishers, Chicago.

Willems, J. L., Poblete, P. F., and Pipberger, H. V. (1972). Day-to-day variation of the normal orthogonal electrocardiogram and vectorcardiogram. Circulation, 45, 1057.

Requests for reprints to Dr. S. Talbot, Division of Cardiovascular Disease, Hammersmith Hospital, Ducane Road, London W12 0HS. 